\title{
BMJ Open A pilot study of an online universal school-based intervention to prevent alcohol and cannabis use in the UK
}

\author{
Nicola C Newton, ${ }^{1,2}$ Patricia J Conrod, ${ }^{2,3}$ Daniel M Rodriguez, ${ }^{1}$ Maree Teesson ${ }^{1}$
}

To cite: Newton NC Conrod PJ, Rodriguez DM, et al. A pilot study of an online universal school-based intervention to prevent alcohol and cannabis use in the UK. BMJ Open 2014:4: e004750. doi:10.1136/ bmjopen-2013-004750

- Prepublication history for this paper is available online. To view these files please visit the journal online (http://dx.doi.org/10.1136/ bmjopen-2013-004750).

Received 2 January 2014 Revised 18 April 2014 Accepted 25 April 2014

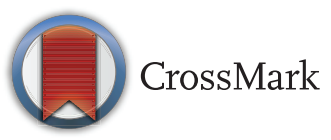

${ }^{1}$ NHMRC Centre for Research Excellence in Mental Health and Substance Use, National Drug and Alcohol Research Centre, University of New South Wales, Sydney, New South Wales, Australia ${ }^{2}$ Institute of Psychiatry, King's College London, London, UK

${ }^{3}$ Department of Psychiatry, Université de Montréal, Montreal, Quebec, Canada

Correspondence to Dr Nicola C Newton; n.newton@unsw.edu.au

\section{ABSTRACT \\ Objectives: The online universal Climate Schools intervention has been found to be effective in reducing the use of alcohol and cannabis among Australian adolescents. The aim of the current study was to examine the feasibility of implementing this prevention programme in the UK. \\ Design: A pilot study examining the feasibility of the Climate Schools programme in the UK was conducted with teachers and students from Year 9 classes at two secondary schools in southeast London. Teachers were asked to implement the evidence-based Climate Schools programme over the school year with their students. The intervention consisted of two modules (each with six lessons) delivered approximately 6 months apart. Following completion of the intervention, students and teachers were asked to evaluate the programme.}

Results: 11 teachers and 222 students from two secondary schools evaluated the programme. Overall, the evaluations were extremely positive. Specifically, $85 \%$ of students said the information on alcohol and cannabis and how to stay safe was easy to understand, $84 \%$ said it was easy to learn and $80 \%$ said the online cartoon-based format was an enjoyable way to learn health theory topics. All teachers said the students were able to recall the information taught, $82 \%$ said the computer component was easy to implement and all teachers said the teacher's manual was easy to use to prepare class activities. Importantly, $82 \%$ of teachers said it was likely that they would use the programme in the future and recommend it to others. Conclusions: The Internet-based universal Climate Schools prevention programme to be both feasible and acceptable to students and teachers in the UK. A full evaluation trial of the intervention is now required to examine its effectiveness in reducing alcohol and cannabis use among adolescents in the UK before implementation in the UK school system.

\section{INTRODUCTION}

Substance use among young people continues to be a serious public health concern. The 2011 European School Survey Project on Alcohol and Other Drugs (EPSAD) examined substance use in over 100000 students

\section{Strengths and limitations of this study}

- A pilot study examining the feasibility of the internet-based Climate Schools programme in the UK was conducted with 222 students and 11 teachers at secondary schools in London.

- Student evaluations were extremely positive with approximately $85 \%$ reporting that the information taught in the programme was easy to understand and learn.

- Teacher evaluations were extremely positive with all teachers reporting that the students were able to recall the information and over $80 \%$ saying that they would be likely to use the programme in the future and recommend it to others.

- Overall, the online school-based Climate Schools prevention programme was found to be feasible and acceptable to students and teachers in the UK.

- A full evaluation trial of the Climate Schools intervention is now required to examine its effectiveness in the UK.

from 36 European countries, including the UK, and found alcohol and cannabis to be the most commonly used licit and illicit drugs, respectively. ${ }^{1}$ On average, $87 \%$ of students reported drinking alcohol at least once in their lifetime, $57 \%$ reported drinking alcohol in the past month, and $39 \%$ reported heavy episodic drinking in the past month (defined as 5 or more drinks on one occasion). Lifetime cannabis use was reported by $17 \%$ of respondents with rates closer to one in four for UK students.

The high prevalence of use among young people is a matter of particular concern considering that such behaviours are associated with significant burden of disease, ${ }^{2}{ }^{3}$ social costs $^{4}$ and increased risk of developing substance use disorders ${ }^{5}{ }^{6}$ and comorbid mental health problems. ${ }^{7}$ To alleviate this burden and reduce the occurrence and cost of such problems, prevention is essential and needs to be initiated early before harmful patterns of drug use are established and begin to cause disability. ${ }^{8}$ 
While prevention strategies do exist, research has not been able to consistently demonstrate that universal school-based drug prevention is effective in reducing actual substance use, ${ }^{10-12}$ and until now there have been no positive evaluations of effective universal interventions to prevent substance use in the UK. This is because the effectiveness of school-based prevention is often compromised by obstacles associated with programme implementation and dissemination, ${ }^{13}{ }^{14}$ and by the adoption of abstinence-as opposed to the successful harm-minimisation approach to prevention. ${ }^{15-18}$

The universal internet-based Climate Schools: Alcohol and Cannabis course was developed to overcome these obstacles and aims to prevent alcohol and cannabis use and related harms among adolescents. The Climate Schools programme is based on the effective harmminimisation approach to prevention and uses cartoon storylines to engage and maintain student interest. ${ }^{19}$ The programme is facilitated by the internet, which guarantees complete and consistent delivery while ensuring high implementation fidelity. The programme is designed to fit within the school health curriculum and be implemented among 13-14-year-olds before significant exposure to alcohol and drug use occurs, and consists of two sets of six lessons delivered approximately 6 months apart over the school year. The efficacy of the Climate Schools programme has been established using a cluster randomised controlled trial (RCT) in 10 secondary schools in Australia $(\mathrm{n}=764) .{ }^{20}{ }^{21}$ Results from the RCT demonstrate that, compared with the control group, students in the intervention group showed significant improvements in alcohol and cannabis knowledge, reductions in average alcohol consumption and binge drinking, and a reduction in frequency of cannabis use up to 12 months following the intervention. In addition, evaluations of the internet-based programme by teachers and students in the trial were extremely positive. Specifically, $90 \%$ of students reported that the information delivered was easy to learn and that they would like to learn other topics through this method; also, all teachers rated the programme as superior to other drug prevention programmes. ${ }^{20} 21$

Given the high prevalence of alcohol and cannabis use among young people along with the clear need for effective universal prevention in the UK, the aim of this pilot study was to examine the feasibility of implementing the Climate Schools programme in the UK school setting. This evidence-based programme was deemed an appropriate choice for adaptation due to similarities between Australia and the UK in terms of youth drinking culture, age of initiation to substance use, and the fact that alcohol and cannabis are the most commonly used licit and illicit drugs, respectively, in both countries. $^{1}{ }^{22}$

Before conducting a full-scale RCT, determining the feasibility and acceptability of an intervention is an important step before evaluating its effectiveness in a new context to ensure that it is relevant, suitable and easy to implement with the target audience. ${ }^{23-25}$ It was expected that teachers and students in the UK who deliver and complete the Climate Schools programme would rate it as (1) easy to implement and understand; (2) an interesting and enjoyable drug education programme and (3) superior to other drug education programmes.

\section{METHOD}

\section{Recruitment of schools}

Letters outlining the aims of the study were emailed to a number of secondary schools who had existing relationships with researchers at the Institute of Psychiatry, Kings College London. Two schools from southeast London agreed to participate. All aspects of the study were approved by the Kings College London Research Ethics Committee.

\section{Participants}

Passive information and consent forms were sent home to parents/guardians of all Year 9 students (13-14-year-olds) from the participating schools $(\mathrm{N}=342)$. Only those students whose parents did not object to their participation in the study, and who gave active written consent themselves, were eligible to participate $(\mathrm{N}=222)$. In addition, active written consent was required from all teachers to participate in the study. Participants were made fully aware that they could withdraw from the study at any time without prejudice.

\section{Procedure}

The two participating schools were asked to implement the Climate Schools: Alcohol and Cannabis course with their Year 9 classes over the school year from 2010 to 2011. Following completion of the intervention, teachers and students were asked to evaluate the programme through anonymous questionnaires which took approximately $10 \mathrm{~min}$ to complete. Teachers were reimbursed $£ 20$ for their time, and students from each class went into a draw to receive a $£ 10$ voucher for their time.

\section{Intervention}

The Climate Schools: Alcohol and Cannabis course is a universal school-based prevention programme which adopts a harm-minimisation framework. It comprises the delivery of two modules (the Alcohol module and the Alcohol and Cannabis module), delivered approximately 6 months apart. Each module includes six 40 min lessons aimed at reducing alcohol and cannabis use and related harms. The first part of each lesson is a 20 min internet-based component completed individually online where students followed a cartoon storyline of teenagers experiencing real-life situations and harms associated with alcohol and cannabis use. The cartoon storyline imparts all the core content of the programme. The second part of each lesson is an optional predetermined activity delivered by the teacher to reinforce the information 
learnt in the cartoons. Teachers are provided with a teaching manual, but no additional training is required in order to implement the course.

As the programme was originally developed in Australia, aspects of the programme content were adapted for the UK before implementation in schools. ${ }^{26} 27$ These included changing standard drinks references to units of alcohol, replacing call centre and emergency numbers with their UK counterparts (eg, 000 swapped for the England emergency number of 999), and replacing Australian slang terms with more common terms used in the UK. Table 1 outlines the content of each lesson. Access to the full UK version of the Climate Schools programme can be found online: http://www.climateschools.co.uk

\section{Measures}

\section{Demographics}

Demographic information was obtained including participant's age, gender as well as number of teaching years for teachers.

\section{Programme evaluation}

Students and teachers were asked to evaluate the programme using questionnaires that have been employed in the previous Australian trial of the Climate Schools programme. $^{21}$

\section{Student evaluation}

Students were asked to evaluate the programme by indicating on a seven-point Likert scale how strongly they agreed or disagreed with 10 statements relating to content of the programme and how enjoyable and interesting they found it to be. Statements included "The cartoon story was an enjoyable way of learning health education", and "The information on alcohol and cannabis and how to stay safe was easy to understand".

\section{Teacher evaluation}

Teachers were asked to evaluate the programme by answering 15 questions relating to programme content, ease of implementation and overall ratings of the programme. Thirteen questions were closed questions with fixed response categories and two were open-ended questions that asked teachers to list ways in which the programme could be improved in the future as well as any additional comments they had. In addition, teachers were asked to record what lessons and activities they delivered to their students.

\section{RESULTS \\ Analyses}

Descriptive statistics of the student and teacher data were obtained using PASW Statistics V.18 and a descriptive quantitative analysis of the open-ended teacher responses was performed.

\section{Sample characteristics}

Two hundred and twenty-two Year 9 students, who received parental consent and consented themselves, participated in the study and completed the student evaluation questionnaire. Students ranged in age from 12 to 15 years with a mean age of 13.86 years $(\mathrm{SD}=0.40)$ and $57 \%$ were female.

Eleven teachers who implemented the Climate Schools course with their students evaluated the programme. Teachers ranged in age from 24-54 years with a mean age of 38.11 years $(\mathrm{SD}=10.47)$ and $91 \%$ were women. The average number of years of teaching was 11 years $(\mathrm{SD}=8.52)$.

\section{Programme evaluation \\ Student evaluation}

Responses to the student evaluation questionnaire are presented in table 2. In regard to the online cartoon storyline, $80 \%$ of students agreed (strongly, moderately or slightly) that the cartoon story was an enjoyable way of learning health education, $78 \%$ agreed that it helped keep their interest while learning, $66 \%$ agreed that it was relevant to experiences in their own lives and $65 \%$ reported that they would like to learn other health theory topics this way. In regard to the information on alcohol and cannabis and how to stay safe, $85 \%$ of students agreed it was easy to understand, $84 \%$ agreed it was easy to learn and $79 \%$ agreed it was easy to remember. When asked to evaluate the optional classroom activities, $67 \%$ of students agreed that the activities helped them further understand the information taught in the lesson and $60 \%$ reported that the activities helped them to apply the information to their own lives. Two-thirds (64\%) of students reported that they planned to use the information learnt in their own lives.

\section{Teacher evaluation}

All teachers reported implementing the programme in its entirety, including the computerised cartoon components and at least one class-based activity for each lesson. Teacher responses to the closed-ended teacher evaluation questions are summarised below.

When asked to evaluate the cartoon storyline, all teachers said that the students were able to recall the information taught, the majority (91\%) said that the students liked the cartoons and $82 \%$ of teachers said that it held the students' attention well. In regard to implementation, $82 \%$ of teachers said it was easy (or very easy) to implement the computer component of the programme, one teacher said it was average, and one said it was difficult. All but one of the teachers (91\%) said it was easy (or very easy) to gain access to computers at their school, and one said it was difficult. All teachers reported that it was easy (or very easy) to use the teacher's manual to prepare class activities and said that the activities helped reinforce the storylines.

When asked to rate the overall programme, all except one of the teachers $(91 \%)$ rated it as very good, good or 
Table 1 Lesson content of the Climate Schools: Alcohol and Cannabis course

\begin{tabular}{|c|c|c|}
\hline Module & Lesson & Content \\
\hline \multirow[t]{6}{*}{ Alcohol } & 1 & $\begin{array}{l}\text { Alcohol, the law and underage drinking } \\
\text { Alcohol units } \\
\text { Guidelines for low-risk drinking limits } \\
\text { Identifying the number of alcohol units in alcohol beverages } \\
\text { Societal pressures and expectations to drink alcohol }\end{array}$ \\
\hline & 2 & $\begin{array}{l}\text { Prevalence and patterns of alcohol consumption among 14-15-year-olds } \\
\text { Alcohol-free social activities } \\
\text { Identifying sources of pressure to drink too much alcohol } \\
\text { Identifying the reasons teenagers choose to drink or not drink alcohol } \\
\text { Dispelling some myths about alcohol: 'coffee sobers you up' }\end{array}$ \\
\hline & 3 & $\begin{array}{l}\text { Short-term and long-term consequences of drinking too much alcohol } \\
\text { Identifying the potential for risk and harm in common teenage drinking scenarios } \\
\text { Exploring ways to prevent alcohol-related harm in common teenage drinking scenarios } \\
\text { Identifying sources of help for teenagers }\end{array}$ \\
\hline & 4 & $\begin{array}{l}\text { Myths and facts about alcohol } \\
\text { Advertising tactics } \\
\text { Alcohol advertising laws } \\
\text { Alcohol advertising and youth }\end{array}$ \\
\hline & 5 & $\begin{array}{l}\text { Drug refusal skills } \\
\text { Ways to minimise alcohol consumption } \\
\text { Tips to keep people safe who are drinking too much alcohol } \\
\text { Decision-making about whether to consume alcohol with the purpose of getting drunk } \\
\text { Examining different views on the consumption of alcohol }\end{array}$ \\
\hline & 6 & $\begin{array}{l}\text { Ways to prevent an alcohol-related medical emergency } \\
\text { Recognising the signs of an alcohol-related medical emergency } \\
\text { What to do if there is a medical emergency? } \\
\text { Whom to contact if there is a medical emergency? } \\
\text { Calling the emergency number '999' } \\
\text { The recovery position }\end{array}$ \\
\hline \multirow[t]{5}{*}{$\begin{array}{l}\text { Alcohol and } \\
\text { cannabis }\end{array}$} & 1 & $\begin{array}{l}\text { Alcohol, the law and underage drinking } \\
\text { Guidelines for low-risk drinking limits } \\
\text { Identifying the number of alcohol units in alcoholic beverages } \\
\text { Prevalence and patterns of alcohol use among 14-15-year-olds } \\
\text { Acute harms/consequences associated with alcohol use }\end{array}$ \\
\hline & 2 & $\begin{array}{l}\text { Alcohol, the law and underage drinking identifying reasons why teenagers choose } \\
\text { to drink or not drink Alcohol-free activities } \\
\text { Acute and chronic harms/consequences of drinking alcohol } \\
\text { Identifying the potential for risk and harm in common teenage drinking scenarios } \\
\text { Exploring ways to prevent alcohol-related harm in common teenage drinking scenarios, for } \\
\text { example, tips to keep people safe who were drinking too much alcohol and ways to minimise } \\
\text { alcohol consumption Drug refusal skills }\end{array}$ \\
\hline & 3 & $\begin{array}{l}\text { The UK guidelines for low-risk drinking limits } \\
\text { Acute and chronic harms/consequences of drinking alcohol } \\
\text { What is cannabis? } \\
\text { Prevalence and patterns of cannabis use among 14-16-year-olds } \\
\text { Identifying reasons why teenagers choose to use or not use cannabis } \\
\text { Acute harms/consequences of using cannabis on health and well-being } \\
\text { Varying effects of cannabis from person to person }\end{array}$ \\
\hline & 4 & $\begin{array}{l}\text { Cannabis and the law } \\
\text { Economic consequences of using cannabis } \\
\text { Acute and chronic harms/consequences of using cannabis on health and well-being } \\
\text { Varying effects of cannabis from person to person } \\
\text { Recognising problems associated with cannabis use } \\
\text { Teaching and responding to risk and harm in common teenage scenarios } \\
\text { Tips to keep people who are using cannabis safe }\end{array}$ \\
\hline & 5 & $\begin{array}{l}\text { Acute and chronic harms/consequences of cannabis on health and well-being } \\
\text { Relationship between cannabis use and mental illness } \\
\text { Identifying reasons why people choose to use or not use cannabis }\end{array}$ \\
\hline
\end{tabular}


Table 1 Continued

\begin{tabular}{ll}
\hline Module Lesson & Content \\
& Recognising problems associated with cannabis use \\
& Seeking help \\
& Dealing and coping with challenging situations \\
& Effects of other people's drug use \\
& Recognising and responding to risks and harms of cannabis \\
& Tips to help friends reduce or cease using cannabis \\
& Alternatives to using cannabis \\
& Identifying when to seek help \\
& Identifying where to seek help, for example, resources and support agencies for teenagers \\
& using cannabis (at school and in the community) \\
\hline
\end{tabular}

average. In comparison to other drug education programmes, three quarters of the teachers $(73 \%)$ rated it as better (or much better) than other programmes with the remaining rating it as the same as other programmes. Importantly, $82 \%$ of teachers said it was likely (or very likely) they would use the programme in the future and recommend it to others.

Two themes arose from the suggestions teachers gave to improving the programme. The first related to shortening the cartoons and/or making them more interactive in order to better hold the student's attention. Specific comments around this included, "Stories need to be shorter and more interesting", "Cartoons need to be shorter to hold the students attention", "One pupil suggested it be a talking cartoon", "Sound effects/music on the cartoon", and "The module could be more interactive". The second theme of suggestions related to repetition in the module due to implementing them so close together. Specific comments around this included, "(there is) Sometimes repetition in lessons on the alcohol and cannabis modules", and "When students have done the alcohol module to do the cannabis and alcohol module straight after makes some of the content a little repetitive". In addition, general comments from teachers regarding the programme were positive and included, "It was fun and different from the usual, and far more interactive" and "On the whole a good pack to use with students".

\section{DISCUSSION}

Prior to evaluating an intervention in a new context, it is important to ensure that it is relevant, suitable and easy to implement with the target audience. ${ }^{23-25}$ The Climate Schools programme is a 12-lesson universal school-based intervention to prevent alcohol and cannabis use and related harms. The programme has previously been found to be effective in reducing the use of alcohol and cannabis among adolescents in Australia; however, it is yet to be trialled internationally. This study aimed to examine the feasibility and acceptability of the online universal Climate Schools: Alcohol and Cannabis course in the UK.
Teachers from two schools in southeast London implemented the 12-lesson programme with their Year 9 students over the year. Following completion of the intervention, students and teachers evaluated the programme to examine its feasibility in the UK school setting. Overall, both the student and teacher evaluations of the programme were extremely positive and are consistent with the positive evaluations received from students and teachers who participated in the Australian RCT of the Climate Schools intervention. ${ }^{21}$

Specifically, the majority of students who received the programme reported that they enjoyed learning health education through the online cartoon-based format and said that it helped keep their interest. The vast majority of students said that the information on alcohol and cannabis and how to stay safe was easy to understand and easy to learn, and two-thirds said they planned to use the information learnt in their own lives.

All teachers reported delivering the programme with high fidelity, in full with their students. All teachers believed students were able to recall the information taught, and the vast majority said students like the online cartoon-based format and that it held students' attention well. Teachers attested to the ease of implementation of the programme, rating the computer-based component as easy to implement and the teacher's manual as easy to use when preparing class activities. Importantly, four-fifths of the teachers reported that it was likely they would use the programme in the future and recommend it to others.

The main areas and suggestions for improving the programme that arose from student and teacher evaluations in the current study were to make the cartoon storylines shorter or more interactive in order to better hold the student's attention, and to deliver the modules further apart as the students found some of the information repetitive. Both these points should be considered and addressed prior to implementing a full-scale trial of the programme's effectiveness in the UK. Overall, these positive evaluations attest to the feasibility and acceptability of implementing an online universal school-based prevention programme for alcohol and cannabis use in the UK. 
Table 2 Student evaluation of the Climate Schools: Alcohol and Cannabis course $(n=222)$

\begin{tabular}{|c|c|c|c|c|c|c|c|}
\hline & $\begin{array}{l}\text { Strongly } \\
\text { agree }\end{array}$ & $\begin{array}{l}\text { Moderately } \\
\text { agree }\end{array}$ & $\begin{array}{l}\text { Slightly } \\
\text { agree }\end{array}$ & Undecided & $\begin{array}{l}\text { Slightly } \\
\text { disagree }\end{array}$ & $\begin{array}{l}\text { Moderately } \\
\text { disagree }\end{array}$ & $\begin{array}{l}\text { Strongly } \\
\text { disagree }\end{array}$ \\
\hline $\begin{array}{l}\text { 1. The cartoon story was an enjoyable way of learning } \\
\text { health education (\%) }\end{array}$ & 39.2 & 23 & 17.6 & 10.8 & 3.6 & 2.3 & 3.6 \\
\hline $\begin{array}{l}\text { 2. The cartoon story helped keep my interest while I learnt } \\
\text { the information (\%) }\end{array}$ & 29.3 & 28.8 & 19.4 & 12.6 & 5.9 & 2.3 & 1.8 \\
\hline $\begin{array}{l}\text { 3. The cartoon story was relevant to current or future } \\
\text { experiences in my life or lives of my peers (\%) }\end{array}$ & 21.6 & 19.4 & 25.2 & 20.3 & 7.2 & 3.2 & 3.2 \\
\hline $\begin{array}{l}\text { 4. The information on alcohol and cannabis and how to } \\
\text { stay safe was easy to understand (\%) }\end{array}$ & 38.3 & 27.9 & 18.9 & 10.4 & 3.2 & 0.9 & 0.5 \\
\hline $\begin{array}{l}\text { 5. The information on alcohol and cannabis and how to } \\
\text { stay safe was easy to learn (\%) }\end{array}$ & 37.8 & 28.8 & 17.1 & 9 & 4.5 & 1.8 & 0.9 \\
\hline $\begin{array}{l}\text { 6. The information on alcohol and cannabis and how to } \\
\text { stay safe was easy to remember (\%) }\end{array}$ & 28.4 & 30.6 & 20.3 & 9.5 & 5.4 & 4.1 & 1.8 \\
\hline $\begin{array}{l}\text { 7. I would like to learn other health theory topics through } \\
\text { cartoon stories (\%) }\end{array}$ & 26.6 & 20.3 & 18 & 15.8 & 8.6 & 3.6 & 7.2 \\
\hline $\begin{array}{l}\text { 8. The classroom activities helped me to further } \\
\text { understand the information (\%) }\end{array}$ & 21.2 & 26.6 & 19.4 & 17.6 & 9.5 & 2.3 & 3.6 \\
\hline $\begin{array}{l}\text { 9. The classroom activities helped me to apply the } \\
\text { information I learnt in the cartoons to my own life (\%) }\end{array}$ & 21.6 & 19.8 & 18.9 & 22.5 & 9.9 & 5 & 2.3 \\
\hline $\begin{array}{l}\text { 0. I plan to use the information I learnt in this programme } \\
\text { in my own life }(\%)\end{array}$ & 26.1 & 15.8 & 21.6 & 21.6 & 7.7 & 1.4 & 5.9 \\
\hline
\end{tabular}


Limitations of the study should be considered when interpreting the results. As this was a pilot study aimed at examining the feasibility of the programme in the UK school setting, the number of schools recruited to the study was small and all schools were located in the same geographic area of southeast London. In addition, approximately one-third of the Year 9 population did not receive consent to participate in the current study. To ensure that the findings from this study are generalisable, it is important to evaluate the programme in a greater and more diverse range of students and schools across the UK. This could be achieved in conjunction with a larger RCT which is needed before any conclusions about the programme's effectiveness can be drawn. Such a trial should include measures of alcohol and cannabis use, intentions to use, and attitudes and knowledge related to these substances. Such a study would also benefit from separately evaluating each lesson and module rather than just the overall programme.

\section{CONCLUSION}

Overall, the online universal Climate Schools: Alcohol and Cannabis course was found to be a feasible and acceptable means of delivering drug education in the UK school system. Given these findings coupled with the positive findings from the Australian trial of the programme, the Climate Schools intervention has the potential to address the clear need for effective alcohol and other drug prevention in the UK. Before implementation of the programme in UK schools, the next step is a full evaluation trial of the Climate Schools intervention with students in the UK to examine its effectiveness. It is expected that the Climate Schools programme will demonstrate similar effects in preventing the use of alcohol and cannabis among adolescents in the UK, as it did in Australia.

Acknowledgements The authors would like to acknowledge Dr Laura Vogl and Professor Gavin Andrews for their work on the initial development and evaluation of the Climate Schools programme in Australia, and Associate Professor Nickolai Titov for modifying the cartoons for use in the UK. We are also extremely grateful to the schools, students and teachers who participated in this research.

Contributors NCN, PJC and MT designed the study and gained ethical approval to conduct the study in schools. NCN and DMR adapted the programme content for use in the UK, recruited schools and oversaw the implementation of the programme and surveys in schools. All authors contributed to the writing of the manuscript.

Funding The initial development and evaluation of the Climate Schools: Alcohol and Cannabis course was funded by the Australian Government Department of Health and the Alcohol Education and Rehabilitation Foundation. The current feasibility trial was supported by Dr Newton's Vice Chancellor Post Doctorate fellowship at the University of New South Wales, Sydney, Australia.

Competing interests None.

Patient consent Obtained.

Ethics approval Kings College London Research Ethics Committee.

Provenance and peer review Not commissioned; externally peer reviewed.

Data sharing statement No additional data are available.
Open Access This is an Open Access article distributed in accordance with the Creative Commons Attribution Non Commercial (CC BY-NC 3.0) license, which permits others to distribute, remix, adapt, build upon this work noncommercially, and license their derivative works on different terms, provided the original work is properly cited and the use is non-commercial. See: http:// creativecommons.org/licenses/by-nc/3.0/

\section{REFERENCES}

1. Hibell B, Guttormsson U, Ahlstrom S, et al. The 2011 ESPAD Report: substance use among students in 36 European countries. Stockholm, Sweden: The Swedish Council for Information on Alcoho and Other Drugs, 2012.

2. Whiteford HA, Baxter AJ, Ferrari AJ, et al. Global burden of disease attributable to mental and substance use disorders: findings from the Global Burden of Disease Study 2010. Lancet 2013;382:1575-86.

3. Degenhardt L, Calabria B, Ferrari AJ, et al. The global epidemiology and contribution of cannabis use and dependence to the global burden of disease: results from the GBD 2010 Study. PLOS ONE 2013;8:e76635.

4. Rehm J, Mathers C, Popova S, et al. Global burden of disease and injury and economic cost attributable to alcohol use and alcohol-use disorders. Lancet 2009;373:2223-33.

5. Behrendt $\mathrm{S}$, Wittchen $\mathrm{H}$, Hofler M, et al. Transitions from first substance use to substance use disorders in adolescence: is early onset associated with a rapid escalation? Drug Alcohol Depend 2009;99:68-78.

6. Grant J, Scherrer J, Lynskey M, et al. Adolescent alcohol use is a risk factor for adult alcohol and drug dependence: evidence from a twin design. Psychol Med 2006;36:109-18.

7. Teesson M, Degenhardt L, Hall W, et al. Substance use and mental health in longitudinal perspective. In: Stockwall T, Grueneald $P$, Toumbourou JLoxley W, eds. Preventing harmful substance use: the evidence base for policy and practice. Chichester: John Wiley and Sons, 2005:43-51.

8. Spooner C, Hall W. Public policy and the prevention of substance-use disorders. Curr Opin Psychiatry 2002;15:235-9.

9. Botvin GJ. Preventing drug abuse in schools: social and competence enhancement approaches targeting individual-level etiologic factors. Addict Behav 2000;25:887-97.

10. Faggiano F, Vigna-Taglianti FD, Versino E, et al. School-based prevention for illicit drugs use: a systematic review. Prev Med 2008;46:385-96.

11. Foxcroft DR, Tsertsvadze A. Universal school-based prevention programs for alcohol misuse in young people. Cochrane Database Syst Rev 2011;(5):CD009113.

12. Werch CE, Owen DM. latrogenic effects of alcohol and drug prevention programs. J Stud Alcohol 2002;63:581-90.

13. Ennett ST, Ringwalt CL, Thorne J, et al. A comparison of current practice in school-based substance use prevention programs with meta-analysis findings. Prev Sci 2003;4:1-14

14. Ringwalt $\mathrm{C}$, Ennett $\mathrm{S}$, Johnson $\mathrm{R}$, et al. Factors associated with fidelity to substance use prevention curriculum guides in the Nation's middle schools. Health Educ Behav 2003;30:375-91.

15. McBride N, Farringdon F, Midford R, et al. Harm minimisation in school drug education: final results of the School Health and Alcohol Harm Reduction Project (SHAHRP). Addiction 2004;99:278-91.

16. Beck J. 100 years of "just say no" versus "just say know": Re-evaluating drug education goals for the coming century. Eval Rev 1998;22:15-45

17. Newton NC, Vogl LE, Teesson M, et al. CLIMATE Schools Alcoho Module: cross-validation of a school-based prevention programme for alcohol misuse. Aust N Z J Psychiatry 2009;43:201-7.

18. Vogl L, Teesson M, Andrews G, et al. A computerised harm minimisation prevention program for alcohol misuse and related harms: randomised controlled trial. Addiction 2009;104:564-75.

19. Schinke S, Schwinn TM, Noia JD, et al. Reducing the risks of alcohol use among urban youth: three-year effects of a computer-based intervention with and without parent involvement. J Stud Alcohol 2004;65:443-9.

20. Newton NC, Andrews G, Teesson M, et al. Delivering prevention for alcohol and cannabis using the internet: a cluster randomised controlled trial. Prev Med 2009;48:579-84.

21. Newton NC, Teesson M, Vogl L, et al. Internet-based prevention for alcohol and cannabis use: final results of the Climate Schools course. Addiction 2010;105:749-59.

22. Australian Institute of Health and Welfare (AlHW). 2010 National Drug Strategy Household Survey Report. Drug Statistics series no. 25. PHE 145. Canberra: AlHW, 2011.

23. Barry M, Domitrovich C, Lara MA. The implementation of mental health promotion programmes. Promot Educ 2005(Suppl 2):30-6. 
24. Midford R, Cahill H, Ramsden R, et al. Alcohol prevention: what can be expected of a harm reduction focused school drug education programme? Drugs Educ Prev Policy 2012:19:102-10.

25. Barrett EL, Newton NC, Teesson M, et al. Adapting the personality-targeted Preventure program to prevent substance use and associated harms among high-risk Australian adolescents. Early Interv Psychiatry 2013. doi:10.1111/eip.12114. http://onlinelibrary. wiley.com/doi/10.1111/eip.12114/abstract; jsessionid=B36CCA411441954DA847B22A32F507E2.f04t02

26. Newton NC, Teesson M, Conrod PJ, et al. Adaptation of the Climate Schools: Alcohol and Cannabis Module for the United Kingdom. United Kingdom Institute of Psychiatry, King's College London, 2010.

27. Newton NC, Teesson M, Conrod PJ, et al. Adaptation of the Climate Schools: Alcohol Module for the United Kingdom. UK: Institute of Psychiatry, King's College London, 2010. 